\title{
Calcium Bentonite as Reinforcing Nanofiller for Thermoplastic Starch
}

\author{
Natália F. Magalhães and Cristina T. Andrade* \\ Instituto de Macromoléculas Professora Eloisa Mano, Universidade Federal do Rio de Janeiro, \\ Centro de Tecnologia, Bloco J, 21945-570 Rio de Janeiro-RJ, Brazil
}

\begin{abstract}
Amidos termoplásticos plastificados com glicerol (TPS), e reforçados com bentonita cálcica, foram preparados por extrusão. A morfologia dos materiais extrusados foi analisada por microscopia eletrônica de varredura. Foram avaliados os efeitos do teor de argila e do teor de glicerol sobre as propriedades físicas dos materiais. Os resultados de difração de raios X mostraram que o aumento no teor de glicerol contribuiu para o aumento da cristalinidade do tipo B. A adição da argila levou a materiais híbridos com propriedades melhoradas em relação ao TPS sozinho, mesmo após o envelhecimento sob condições de umidade relativa do ar de $80 \%$ durante 90 dias. A difração de raios $\mathrm{X}$ também permitiu a avaliação da intercalação da argila na matriz de amido, antes e após o condicionamento. Resultados de testes mecânicos sob tensão uniaxial sugeriram um alto grau de exfoliação.
\end{abstract}

Glycerol-plasticized corn starch materials (TPS), reinforced with calcium bentonite, were prepared by melt extrusion. Scanning electron microscopy was used to visualize extrudates morphology. The effects of clay content and of glycerol content on physical properties of extrudates were evaluated. As determined by X-ray diffraction, the increase in glycerol content led to materials with higher B-type crystallinity. Addition of clay resulted in hybrid materials with improved properties in relation to TPS alone, even after conditioning at a high relative humidity for 90 days. X-Ray diffraction was also used to evaluate clay intercalation within the polymeric matrix, before and after conditioning. Results from tensile tests suggested a high degree of exfoliation.

Keywords: thermoplastic starch, calcium bentonite, hybrids, aging, mechanical properties

\section{Introduction}

Hybrid materials, such as organic polymer/inorganic filler composites, have been developed for decades. Addition of filler was shown to improve the stiffness and strength of polymeric materials. Recently, silicate type clays like montmorillonite (the major constituent of bentonites) have received much attention as non-conventional reinforcing fillers. The reason for this interest is related to their potential ability to be exfoliated, at least partially, into nanometric high aspect ratio platelets, which can be dispersed within polymer matrices, and thus favorably modify polymer properties. In general, thermal, mechanical, flammability and barrier properties of the matrix polymer are improved by addition of clay nanofillers.

The most commonly used routes to achieve exfoliation and dispersion of clays are in situ polymerization,

*e-mail: ctandrade@ima.ufrj.br intercalation from solution, and melt-processing. Melt processing has advantages because it does not require the use of solvents. However, intrinsic incompatibility of hydrophilic layered silicates and hydrophobic synthetic plastics usually causes a loss in mechanical properties. Modification of natural clay surfaces by cation exchange reactions is frequently carried out to expand the distance between clay galleries, reduce the surface energy, and improve adhesion. Exchangeable cations like $\mathrm{Na}^{+}$and $\mathrm{Ca}^{2+}$ have been replaced by organic quaternary ammonium salts. ${ }^{1-4}$ Such procedure is believed to favor penetration of polymeric chains into clay galleries, and the subsequent exfoliation by mechanical shearing.

Several studies have been carried out on synthetic polymers/organoclay nanocomposites, and have been the subject of recent reviews. ${ }^{5-9}$

Nowadays, the environmental impact caused by the disposal of plastic waste in nature has contributed to the development of biodegradable polymers. These materials 
are supposed to substitute synthetic polymers, at least in some applications. Starch may be considered one of the most promising materials to be used as a biodegradable thermoplastic. The interest in nonfood uses of starch is justified by its complete biodegradability and worldwide availability from cereal and other crops, at a low cost.

Native starch can be transformed into a thermoplastic material (TPS) through thermomechanical treatment in the presence of suitable plasticizers, such as water and glycerol. The sensitivity of TPS to the humidity atmosphere has been a drawback for its commercial use because its mechanical behavior is dependent on water content. ${ }^{10}$ Within the new paradigm for the fabrication of materials derived from renewable sources, ${ }^{11}$ the possibility of improving the properties of thermoplastic starch by melt-extrusion compounding with clays resulted in several publications. ${ }^{12-20} \mathrm{X}$-ray diffraction, scanning and transmission electron microscopy were used to investigate dispersion and exfoliation of clays within starch matrices from various sources. The effect of processing conditions, ${ }^{16}$ and of the type and content of clay, ${ }^{13,17}$ on properties of nanocomposites, were evaluated. High levels of plasticizers and two-step extrusion procedures were used by some of those authors. Sodium or organically modified clays are the only nanofillers used up to now.

In the present work, regular corn starch plasticized with glycerol was extruded with addition of different amounts of calcium bentonite, a natural clay found in Brazil. The effects of clay content and of glycerol content on the thermal, morphological, and mechanical properties of the resulting materials were investigated. Aging of extruded TPS and hybrid materials was accompanied after conditioning at $28{ }^{\circ} \mathrm{C}$ and $80 \%$ relative humidity for 90 days by $\mathrm{X}$-ray diffraction measurements.

\section{Experimental}

\section{Materials}

Regular cornstarch (CS) composed of 26-30\% amylose and $74-70 \%$ amylopectin, and with less than $0.5 \%$ gluten, and $12 \%$ moisture content was supplied by Corn Products Brazil (São Paulo, SP, Brazil). Analytical grade glycerol was purchased from Vetec Química Fina Ltda. (Rio de Janeiro, RJ, Brazil) and was used as received. Naturally occurring calcium bentonite (NT25) was supplied by Bentonit União do Nordeste S.A. (Campina Grande, PB, Brazil).

\section{Preparation of samples}

CS and glycerol were premixed in a conventional mixer (Ika Works, Wilmington, NC, USA) for $10 \mathrm{~min}$, and maintained in sealed bags for 10 days at $4{ }^{\circ} \mathrm{C}$. Clay was mixed with CS/ glycerol premixtures shortly before extrusion.

\section{Melt extrusion}

Plasticized CS and CS/ clay mixtures were manually fed and processed in a Haake Rheocord 9000 system (Karlsruhe, Germany), equipped with a single-screw extruder, and four heating zones. The barrel length-todiameter ratio was 25:1. The screw speed was maintained constant at $40 \mathrm{rpm}$, and the temperatures of the heating zones were $90,105,105$, and $90^{\circ} \mathrm{C}$ from feed zone to die end. The samples were extruded into sheet form via an attached $25.0 \mathrm{~mm} \times 1.0 \mathrm{~mm}$ die.

\section{Scanning electron microscopy}

The morphology of the samples was observed with a Jeol electron microscope, model JSM-5610LV (Akishimashi, Japan). Samples were cooled in liquid nitrogen, and then fractured. The fractured surfaces were vacuum-coated with gold before measurements.

\section{Thermogravimetric analysis}

Thermogravimetric analyses were carried out on a TGA Q-500 equipment from TA Instruments (New Castle, USA). Approximately, $10 \mathrm{mg}$ of sample were heated from 50 to $700{ }^{\circ} \mathrm{C}$, at a $10^{\circ} \mathrm{C} / \mathrm{min}$ rate, under nitrogen atmosphere.

\section{$X$-Ray diffraction (XRD)}

XRD curves for NT25, native CS, TPS, and TPS/ clay hybrids were obtained with a Miniflex diffractometer (Rigaku Corporation, Osaka, Japan) operating at $\mathrm{CuK} \alpha$ wavelength of $1.542 \AA$. The samples were exposed to the $\mathrm{X}$-ray beam with the X-ray generator running at $30 \mathrm{kV}$ and $15 \mathrm{~mA}$. Scattered radiation was detected at ambient temperature in the angular region $(2 \theta)$ of $2-35^{\circ}$ at a rate of $1 \% \mathrm{~min}$ and a step size of $0.05^{\circ}$. Diffractograms were smoothed (Savitsky-Golay, polynome $=2$, points $=7$ ), and the baseline was corrected. The relative crystallinity of types $\mathrm{B}$ and $\mathrm{V}_{\mathrm{H}}$ were determined according to the method described in the literature,$^{21}$ by dividing the height of the crystalline peak, around $17^{\circ}(2 \theta)$ and $19^{\circ}(2 \theta)$, respectively, by the total height from the baseline. XRD curves for TPS and TPS/NT25 hybrids were obtained before and after conditioning at $28{ }^{\circ} \mathrm{C}$ and $80 \% \mathrm{RH}$, in a climate-controlled chamber M.S. Mistura, model MS 012 (Rio de Janeiro, RJ, Brazil), for 90 days. 


\section{Tensile tests}

Tensile tests were carried out on an Instron Universal Testing Machine model 4204 equipped with a $1 \mathrm{kN}$ load cell, at a speed of $1 \mathrm{~mm} / \mathrm{min}$, according to ASTM D-882 (ASTM, 2002). Retangular samples were conditioned at the same conditions of the test $\left(21^{\circ} \mathrm{C}, 50 \%\right.$ relative humidity) for $48 \mathrm{~h}$ before the experiment. The average value from a total of nine measurements was taken. Young's modulus, $\mathrm{E}$, was determined as

$\mathrm{E}=\frac{\mathrm{L}_{\mathrm{o}}}{\mathrm{A}_{\mathrm{o}}} \frac{\Delta F}{\Delta L}$

where $\mathrm{L}_{\mathrm{o}}$ is the initial height and $\mathrm{A}_{\mathrm{o}}$ is the initial crosssection of the probe, and $\frac{\Delta F}{\Delta L}$ is the initial slope of the stress versus elongation curve.

\section{Experimental design and statistical analysis}

A central composite design was constructed on five levels of two independent variables, i.e. clay content and glycerol content. The design comprised twelve combinations of variable levels for each type of clay, with four replications at the central point (Table 1). The parameters ranges were chosen on the basis of preliminary experiments, performed in an internal mixer.

Table 1. Coded levels for the central composite design

\begin{tabular}{lccccc}
\hline Independent variables & \multicolumn{5}{c}{ Levels } \\
\cline { 2 - 6 } & $-\alpha^{\mathrm{a}}$ & -1 & 0 & +1 & $+\alpha^{\mathrm{a}}$ \\
\hline Clay content $^{\mathrm{b}}$ (wt.\%) & 0.34 & 2.0 & 6.0 & 10.0 & 11.65 \\
Glycerol content $^{\mathrm{b}}$ (wt.\%) & 20.75 & 22.0 & 25.0 & 28.0 & 29.24 \\
\hline
\end{tabular}

${ }^{\mathrm{a}} \alpha=1.414$; ${ }^{\mathrm{b}} \mathrm{Clay}$ content and glycerol content were based on corn starch dry fraction.

The response variables were B-type crystallinity (determined for the hybrids before and after conditioning for 90 days, at $28^{\circ} \mathrm{C}$ and $80 \% \mathrm{RH}$ ), Young's modulus, stress at break and elongation at break (determined for the hybrid samples without conditioning). A second-order polynomial model for dependent variables was established to fit the experimental data. The analysis of variance (ANOVA) was carried out using Statistica for Windows 6.0 (Statsoft Inc., Tulsa, OK, USA) to determine the significance at the $5 \%$ $(\mathrm{P} \leq 0.05)$ level, for linear, quadratic and interaction effects.

\section{Results and Discussion}

TPS and TPS hybrid films prepared by melt-extrusion were homogeneous. Although colored by addition of clay, the films were transparent. This result suggested low degree of crystallinity, and the presence of well-dispersed particles within the starch matrix.

The morphology of TPS and TPS/ clay hybrids was investigated by scanning electron microscopy (SEM). Figures 1 $(a, b)$ show the micrographs of the fractured surface of a TPS sample, processed with $25 \mathrm{wt}$ \% glycerol. In this figure, surface features consist of ghosts (the remaining part of the starch granule), embebbed in a matrix composed mostly of amylose. ${ }^{22-24}$ At the same magnifications, Figures $1(\mathrm{c}, \mathrm{d})$ show the morphology of the fractured surface of TPS/ NT25 hybrid with 11.65 wt.\% clay. In Figure 1c, an increase in roughness may be observed, together with the presence of a tactoid $20 \mu \mathrm{m}$ in length, approximately. Smaller tactoids are also observed in Figure 1d. These results reveal that the processing conditions were not efficient enough to completely exfoliate clay particles.
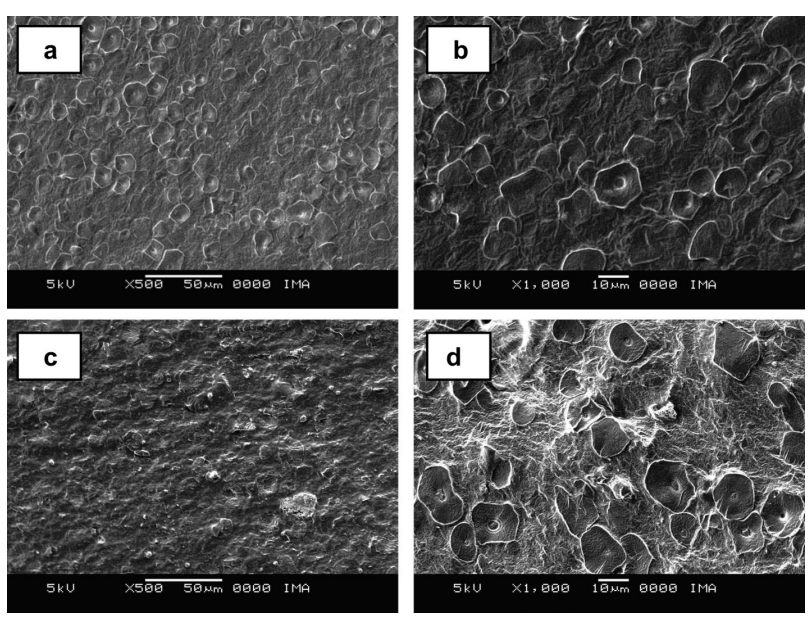

Figure 1. SEM images for fractured surfaces of TPS alone $(a, b)$, and TPS/ 11.65 wt.\% NT25 hybrid (c,d), plasticized with 25 wt.\% glycerol.

The thermal stability of TPS and TPS/NT25 hybrids, plasticized with $25 \mathrm{wt}$ \% glycerol, was evaluated by thermal gravimetric analysis (TGA) under nitrogen atmosphere. The TGA curves for neat clay, TPS, and hybrids are shown in Figure 2. Up to $100{ }^{\circ} \mathrm{C}$, mass loss is mainly attributed to water loss. From $100{ }^{\circ} \mathrm{C}$ to decomposition temperature, the mass loss observed for TPS and TPS/NT25 hybrids may be attributed to plasticizer evaporation. The onset degradation temperature increased moderately $\left(5-10{ }^{\circ} \mathrm{C}\right)$ for the filled samples, when compared with TPS alone. It is worth observing in Figure 3 (DTG curves) that the maximum degradation rate was reached at the highest temperature $\left(310^{\circ} \mathrm{C}\right)$ for the TPS/NT25 hybrid with 0.34 wt.\% clay. TPS/ NT25 hybrids with higher clay contents had maximum degradation rates at lower temperatures than TPS alone $\left(300^{\circ} \mathrm{C}\right)$. In these cases, the possibility of the catalytic effect of acidic sites of 


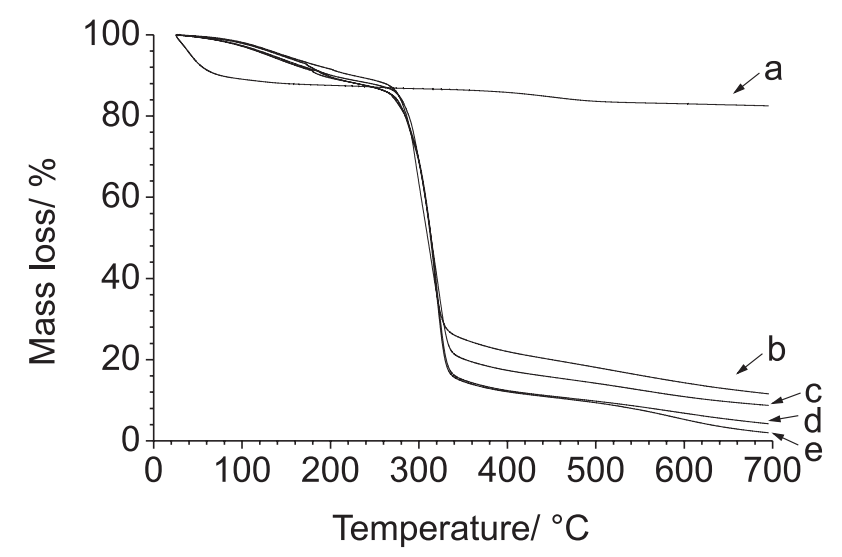

Figure 2. TGA curves for NT25 (a), TPS alone (d), and TPS/ NT25 hybrids with 0.34 wt.\% (e), 6 wt.\% (c), and 11.65 wt.\% (b) clay, plasticized with 25 wt. $\%$ glycerol.

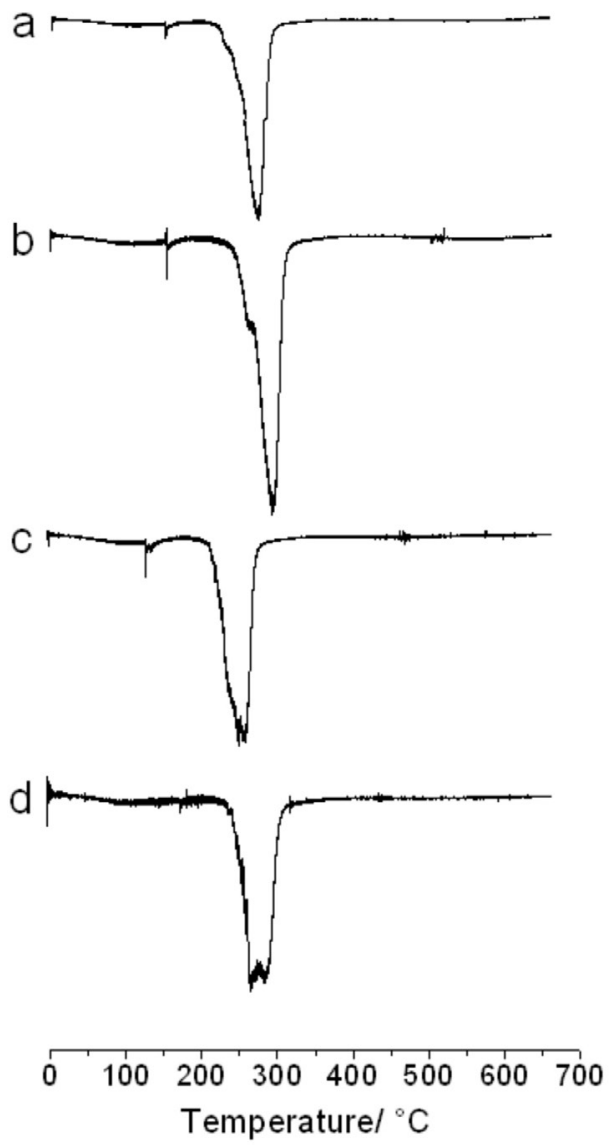

Figure 3. DTG curves for TPS alone (a), and TPS/ NT25 hybrids with 0.34 wt.\% (b), 6 wt.\% (c), and 11.65 wt.\% (d) clay, plasticized with 25 wt. $\%$ glycerol.

montmorillonite on the thermal degradation of the starch matrix may be considered. ${ }^{4}$

Aging of starch gels,${ }^{25}$ films, ${ }^{26}$ and extruded plasticized samples is usually associated with the conversion from an amorphous to a crystalline form. ${ }^{21}$ This phenomenon, known as retrogradation, involves mainly the formation of amylose double helices, and is favored by increasing mobility of starch molecules, caused by water absorption. These effects lead to undesirable changes in mechanical properties, and to crystallization into the B-type lattice, even when the native starch presents A-type crystallinity (cereal starches). Retrogradation may be identified by the presence of a crystalline peak around $17^{\circ}(2 \theta)$.

The crystallinity of TPS, plasticized with 25 wt. $\%$ glycerol, was investigated by XRD, before and after conditioning at $28{ }^{\circ} \mathrm{C}$ and $80 \%$ relative humidity (RH). Figure 4 shows diffractograms obtained for granular regular starch, and for TPS samples. The well-known pattern, ${ }^{27,28}$ described for the A-type crystallinity of granular corn starch may be visualized in trace I. No residual A-type crystallinity was detected for extruded TPS samples, as can be observed in trace II, for a sample analyzed without conditioning, 5 days after processing. This result indicates that shear and temperature conditions during extrusion were adequate to melt granular crystallites. The characteristic peak around $19^{\circ}(2 \theta)$, attributed to processing-induced crystallinity of single helical amylose, and denoted as $\mathrm{V}_{\mathrm{H}}$, was observed for all samples. This peak was found in extruded and compression-molded TPS with more than $10 \%$ water. ${ }^{29}$ Aging at $28{ }^{\circ} \mathrm{C}$ and $80 \% \mathrm{RH}$ for 30 days or longer periods gave rise to the peak at $17.2^{\circ}(2 \theta)$, attributed to the B-type crystallinity. Although the $\mathrm{V}_{\mathrm{H}}$-type crystallinity was maintained nearly constant, increasing B-type crystallinities were determined after aging (traces IV and V).

XRD experiments were also performed for TPS/NL25 hybrids according to the experimental design, with the aim to evaluate the effects of clay and glycerol addition on B-type crystallinity. For these samples, ANOVA revealed

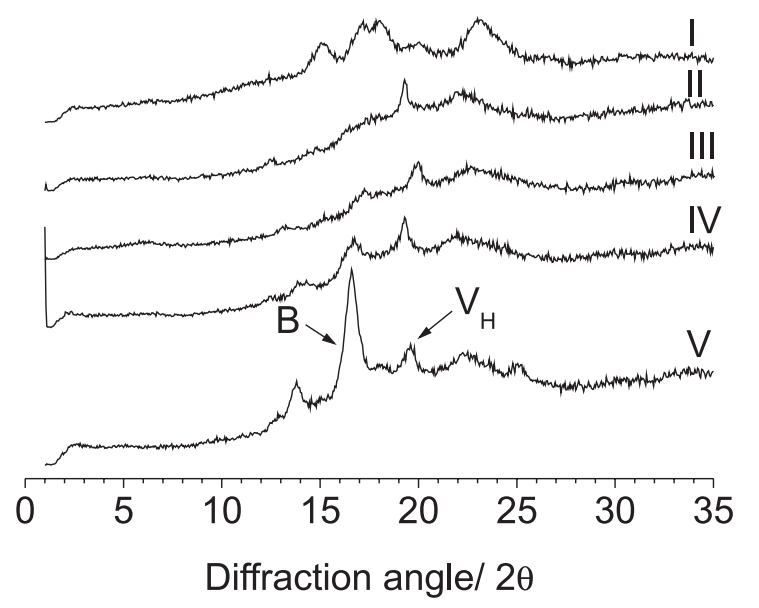

Figure 4. X-ray diffractograms for granular CS (I), and for TPS samples, after extrusion with $25 \mathrm{wt} . \%$ glycerol (II), and after conditioned at $28^{\circ} \mathrm{C}$ and $80 \%$ RH for 30 (III), 60 (IV) and 90 days (V). 
that the positive linear effects of both variables were the most significant $(\mathrm{P}<0.001)$.

Figure 5 shows diffractograms obtained for TPS/NT25 hybrids plasticized with $25 \mathrm{wt} . \%$ glycerol, before and after conditioning for 90 days. In these figures, the diffractogram for TPS alone (trace I), submitted to the same conditions, and for neat NT25 bentonite (trace V) were also included for a better visualization. These diffractograms allow the analysis of the effect of clay content and of aging on the crystallinity of hybrid materials.

No B-type crystallinity peak around $17^{\circ}(2 \theta)$ was detected for the samples analyzed after 5 days of processing (Figure 5a). After 90 days of conditioning, although the peak attributed to B-type crystallinity increased significantly in intensity for TPS alone, only a slight increase in B-type crystallinity was observed for the hybrids (Figure 5b).
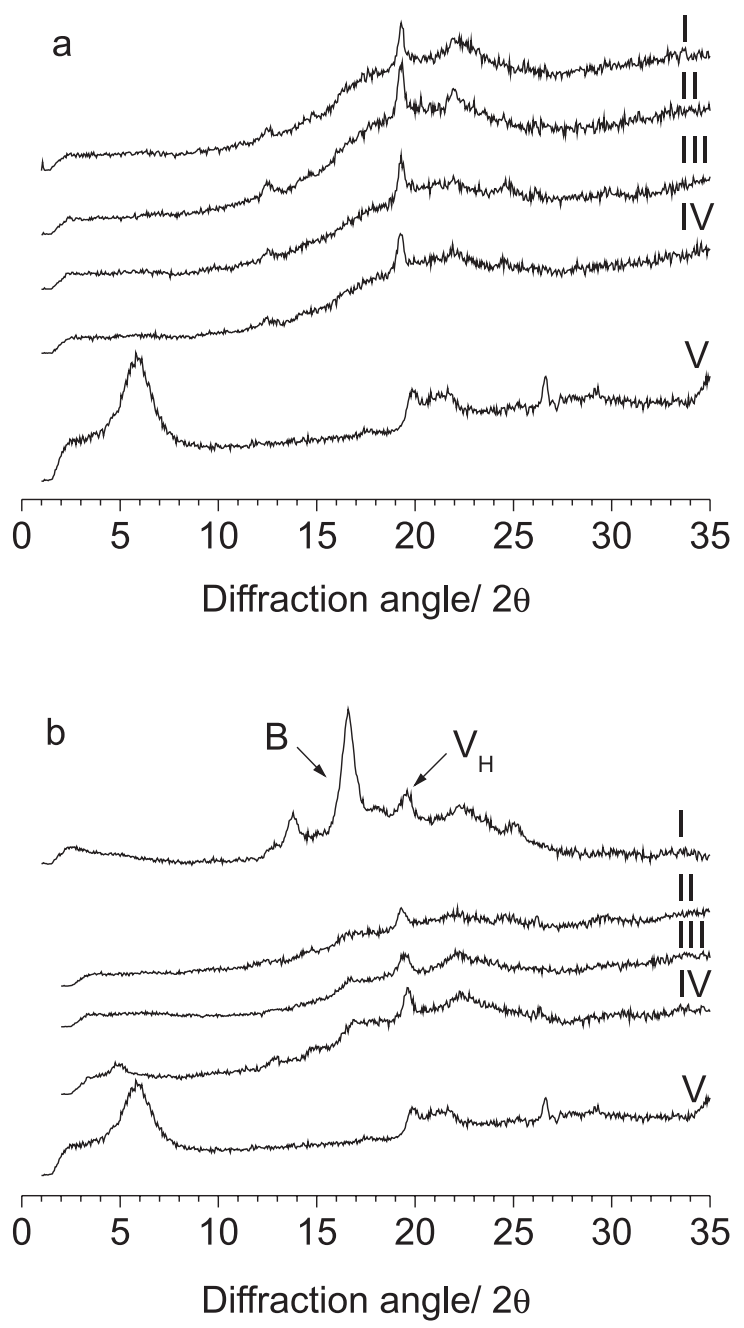

Figure 5. X-Ray diffractograms for TPS alone (trace I), for neat NT25 (trace V), and for TPS/ NT25 hybrids with 0.34 wt.\% clay (trace II), with 6.0 wt.\% clay (trace III), and with $11.6 \mathrm{wt}$.\% clay (trace IV), before conditioning (a), and after conditioning for 90 days (b). TPS and hybrid materials were plasticized with 25 wt. $\%$ glycerol.
It was reported that nucleation of matrix crystallization was observed for some synthetic polymer/clay systems at low levels of clay addition. ${ }^{30-32}$ Contrarily, the crystallization rate was lowered, and crystal growth was probably disturbed, when a sufficiently high level of nanoparticles was added. ${ }^{32-34}$ The reduced relative crystallinities observed for TPS/NL25 hybrids, in relation to TPS alone may be attributed to well-dispersed particles within the polymeric matrix, which may have retarded and unfavored regular packing of starch macromolecules helices. As observed for other TPS/clay systems, ${ }^{20}$ the difference in crystallization behavior between synthetic polymers and TPS systems may be attributed to the higher molecular weight of starch macromolecules.

The diffractograms of Figure 5 also allow the comparison of XRD patterns at lower diffraction angles. The XRD curve for neat NT25 (trace V) shows a peak with high intensity around $5.78^{\circ}(2 \theta)$, corresponding to an interlayer basal spacing ( $d_{001}$-spacing) of $1.53 \mathrm{~nm}$. For TPS/ NT25 hybrids measured before conditioning, no diffraction peak within the 2 to $10^{\circ}(2 \theta)$ range was observed. Although no crystalline peak was observed for conditioned hybrids with 0.34 and 6.0 wt.\% clay, intercalated structures was evidenced by XRD peaks for the conditioned sample with the highest concentration of clay.

Tensile tests were carried out for unconditioned samples, prepared according to the statistical design. Young's modulus values were most significantly affected by the negative linear effect of glycerol, followed by the positive linear effect of clay. The negative linear effect of glycerol was also the most significant effect on stress at break, followed by the negative quadratic effect of glycerol, the positive effect of glycerol/clay interaction, and the positive linear effect of clay. Elongation at break was most affected by the positive linear effect of glycerol, followed by the negative interaction effect, and by the negative linear effect of clay.

The mechanical properties of TPS and TPS/NT25 hybrids, plasticized with 25 wt.\% glycerol, may be visualized in Figure 5. Young's modulus values increased from $88.7 \pm 8.9 \mathrm{MPa}$ to $115.4 \pm 4.7 \mathrm{MPa}$, for clay contents of 0.34 and $11.65 \mathrm{wt} . \%$. These values were intermediate between $44.4 \pm 7.8 \mathrm{MPa}$ and $157.22 \pm 5.4 \mathrm{MPa}$, found for hybrids prepared with 2 wt. $\%$ clay and 28 wt. $\%$ glycerol, and 10 wt. $\%$ clay and 22 wt. $\%$ glycerol, respectively. Elongation at break reached $54.0 \pm 1.7 \%$ for the hybrid sample prepared with 2 wt.\% clay and plasticized with 28 wt.\% glycerol.

For the TPS/NT25 hybrids plasticized with 25 wt.\% glycerol, elongation at break remained practically constant (around 40\%) for increasing contents of clay from 0.34 to 


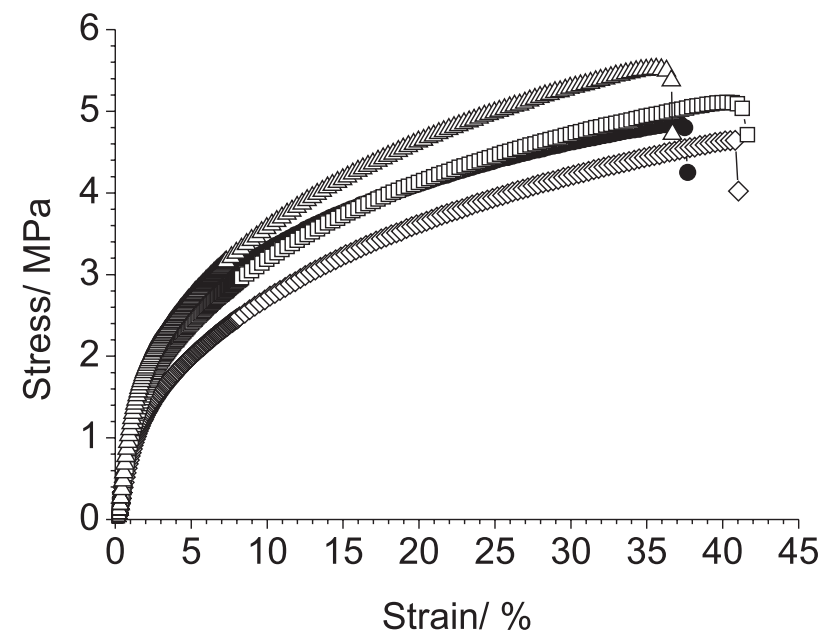

Figure 6. Mechanical properties for TPS alone (๑), and for TPS/ NT25 hybrids with 0.34 wt.\% clay $(\diamond)$, with 6.0 wt.\% clay $(\square)$, and with 11.65 wt. $\%$ clay $(\triangle)$.

$6.0 \mathrm{wt} . \%$. A relatively slight decrease in elongation at break was observed for TPS hybrids extruded in the presence of 11.65 wt.\% clay. In general, for conventional composites, elongation at break decreases sharply with the increase in filler content. ${ }^{3}$ This result corroborates XRD data, and is an indication that the extrusion conditions were adequate to achieve dispersion of clay particles, and a sufficiently high degree of exfoliation.

Accordingly, a study reported elsewhere had as objective to investigate intercalation and exfoliation processes. To examine the effect of the degree of clay exfoliation on the mechanical properties of nanocomposites, some samples were prepared with different levels of exfoliation. The results revealed that the best enhancement in modulus was found for the sample with intermediate level of exfoliation, prepared under mild shearing conditions. Stacks of 1020 lamellae were observed to provide better mechanical properties. ${ }^{35}$ In our case, the mild conditions used for extrusion and the favorable interactions between the hydrophilic starch matrix and the nonorganically-modified clay surface might explain the results.

\section{Conclusion}

TPS and TPS/clay hybrids, plasticized with glycerol, were prepared by melt-extrusion in a single-screw extruder under the same conditions. Natural calcium bentonite was used. A central composite design was constructed to investigate the effect of clay content and of glycerol content on B-type crystallinity and mechanical properties of nanocomposites. XRD results revealed that the increase in glycerol content led to materials with higher B-type crystallinity. Contrarily, addition of clay contributed to minimize B-type crystalinity, and thus to retard starch matrix retrogradation. For materials plasticized with $25 \mathrm{wt} . \%$ glycerol, the appearance of a diffraction peak characteristic of intercalated clay was detected only for the hybrid with the highest clay content, and after aging for 90 days at high humidity conditions. Although tactoids were observed by scanning electron microscopy, the results from tensile tests suggested a high degree of exfoliation. Improved properties in relation to thermoplastic starch alone may be attributed to mild extrusion conditions and a favorable interaction starch/hydrophilic clay surface.

\section{Acknowledgements}

The authors thank the financial support of Conselho Nacional para o Desenvolvimento Científico e Tecnológico (CNPq), Fundação de Amparo à Pesquisa do Estado do Rio de Janeiro (Processo ${ }^{\circ}$ E-26/152.719/2006), and Projeto Encomenda Transversal FINEP/ 01.06.1208.00 - Ref. 3733/06.

\section{References}

1. Vaia, R. A.; Jandt, K. D.; Kramer, E. J.; Giannelis, E. P.; Macromolecules 1995, 28, 8086.

2. Vaia, R. A.; Giannelis, E. P.; Macromolecules 1997, 30, 7990.

3. Cho, J. W.; Paul, D. R.; Polymer 2001, 42, 1083.

4. Ramos Filho, F. G.; Mélo, T. J. A.; Rabello, M. S.; Silva, S. M. L.; Polym. Degrad. Stab. 2005, 89, 383.

5. Alexandre, M.; Dubois, P.; Mater. Sci. Eng. 2000, $28,1$.

6. Ray, S. S.; Okamoto, M.; Progr. Polym. Sci. 2003, 28, 1539.

7. Hussain, F.; Hojjati, M.; Okamoto, M.; Gorga, R. E.; J. Compos. Mater. 2006, 40, 1511.

8. Paul, D. R.; Robeson, L. M.; Polymer 2008, 49, 3187.

9. Pavlidou, S.; Papaspyrides, C.D.; Progr. Polym. Sci. 2008, 33, 1119.

10. van Soest, J. J. G.; Benes, K.; de Wit, D.; Vliegenthart, J. F. G.; Polymer 1996, 37, 3543.

11. Rippel, M. M.; Galembeck, F.; J. Braz. Chem. Soc. 2009, 20, 1024.

12. McGlashan, S; Halley, P.; Polym. Int. 2003, 52, 1767.

13. Park, H.-M.; Lee, W.; Park, C.-Y.; Cho, W.-J.; Ha, C.-S.; J. Mater. Sci. 2003, 38, 9095.

14. Huang, M.; Yu, J.; Ma, X.; Polymer 2004, 45, 7017.

15. Huang, M.; Yu, J.; Ma, X.; Jin, P.; Polymer 2005, 46, 3157.

16. Chiou, B.-S.; Yee, E.; Wood, D.; Shey, J.; Glenn, G.; Orts, W.; Cereal Chem. 2006, 83, 300.

17. Huang, M.; Yu, J.; J. Appl. Polym. Sci. 2006, 99, 170.

18. Huang, M.; Yu, J.; Ma, X.; Carbohydr. Polym. 2006, 63, 393.

19. Dean, K.; Yu, L.; Wu, D. Y.; Compos. Sci. Technol. 2007, 67, 413. 
20. Magalhães, N. F.; Andrade, C. T.; Carbohydr. Polym. 2009, 75, 712.

21. Hulleman, S. H. D.; Kalisvaart, M. G.; Janssen, F. H. P.; Feil, H.; Vliengenthart, J. F. G.; Carbohydr. Polym. 1999, 39, 351.

22. Fannon, J. E.; BeMiller, J. N.; Cereal Chem. 1992, 69, 456.

23. Prentice, R. D. M.; Stark, J. R.; Gidley, M. J.; Carbohydr. Res. 1992, 227, 121.

24. Thiré, R. M. S. M.; Simão, R. A.; Andrade, C. T.; Carbohydr. Polym. 2003, 54, 149.

25. Miles, M. J.; Morris, V. J.; Orford, P. D.; Ring, S. G.; Carbohydr. Polym. 1985, 135, 271.

26. Rindlav, A.; Hulleman, S. H. D.; Gatenholm, P.; Carbohydr. Polym. 1997, 34, 25.

27. van Soest, J. J. G.; Vliegenhart, J. F. G.; Trends Biotechnol 1997, 15, 208.

28. Vermeylen, R.; Goderis, B.; Reynaers, H.; Delcour, J. A.; Biomacromolecules 2004, 5, 1775.
29. van Soest, J. J. G.; Hulleman, S. H. D.; de Wit, D.; Vliegenthart, J. F. G.; Ind. Crop. Prod. 1996, 5, 11.

30. Lincoln, D. M.; Vaia, R. A.; Krishnamoorti, R.; Macromolecules 2004, 37, 4554.

31. Homminga, D.; Goderis, B.; Hoffman, S.; Reynaers, H.; Groeninckx, G.; Polymer 2005, 46, 9941.

32. Homminga, D.; Goderis, B.; Dolbnya, I.; Reynaers, H.; Groeninckx, G.; Polymer 2005, 46, 11359.

33. Fornes, T. D.; Paul, D. R.; Polymer 2003, 44, 3945.

34. Homminga, D.; Goderis, B.; Dolbnya, I.; Groeninckx, G.; Polymer 2006, 47, 1620.

35. Bousmina, M.; Macromolecules 2006, 39, 4259.

Received: March 3, 2009 Web Release Date: November 6, 2009 